\title{
Monetary policy and the natural rate of interest
}

\author{
Matthew Canzoneri, ${ }^{1}$ Robert Cumby ${ }^{2}$ and Behzad Diba ${ }^{3}$
}

\begin{abstract}
We identify the economic environments in which it is most important for monetary policy to be able to track the natural rate of interest. To do this, we study two models: one is a standard New Keynesian model; in the other, government spending shocks move the natural rate of interest away from its steady state value and for a protracted period of time. Policy rules that cannot make the policy rate track the natural rate precisely perform poorly in both of these environments. These rules are especially bad in the second model, where the natural rate movements are sustained and the policy rate cannot catch up. In this model, households would give up half a per cent of their consumption each period to have a rule that can track the natural rate. Even in the standard model, households would give up a quarter of a per cent of consumption to obtain such a rule. Consistent with earlier literature, first difference rules perform quite well in this situation, and they do not require any information about the natural rate of interest. In the current climate of big spending cuts, our results suggest central banks would do well to maintain unusually high inertia in their interest rate setting.
\end{abstract}

Keywords: Monetary policy, natural interest rate, government bonds

JEL classification: E52, E43

\footnotetext{
1 Georgetown University, canzonem@georgetown.edu

2 Georgetown University, cumbyr@georgetown.edu

3 Georgetown University, dibab@georgetown.edu
} 


\section{Introduction}

"One can only say that if the bank policy succeeds in stabilizing prices, the bank rate must have been brought in line with the natural rate."

Orphanides and Williams (2002)

Why is the natural rate of interest so important for inflation control ${ }^{4}$ Consider a variant of the Taylor Rule. ${ }^{5}$

$i_{t}=i_{t}^{n}+1.5\left(\pi_{t}-\bar{\pi}\right)$

where $\pi_{t}$ is the rate of inflation, $\bar{\pi}$ is the inflation target, $i_{t}$ is the policy instrument, and $i_{t}^{n}$ is its natural rate - defined as the rate that would prevail if there were no nominal rigidities. Inflation is brought to its target if the policy rate is brought to its natural rate. Intuitively, when an increase in aggregate demand, or a decrease in productivity, pushes inflation above its target, the policy rate should be raised above its natural rate for a period of time, raising the real rate of interest to curb the rise in inflation. ${ }^{6}$

The problem here is of course that the natural rate of interest is not observed directly, and estimating it is known to be difficult. In an early paper on the subject, Laubach and Williams (2003) found considerable movement in their (imprecise) estimates of the natural rate; they concluded that "...this source of uncertainty needs to be taken account of in analysing monetary policies that feature responses to the natural rate of interest".

Nevertheless, Curdia, Ferrero, Ng and Tambalotti (2011) argue that the Federal Reserve has a history of trying to track the natural rate. They quote Alan Greenspan as saying, "... In assessing real rates, the central issue is their relationship to an equilibrium interest rate, specifically, the real rate level that, if maintained, would keep the economy at its production potential over time. Rates persisting above that level, history tells us, tend to be associated with slack, disinflation, and economic stagnation - below that level with eventual resource bottlenecks and rising inflation ...". Moreover, the authors show that the assumption of such a policy helps New Keynesian models fit the data better.

The conventional view is that observing the natural rate (or being able to make the policy rate track it closely) is very important for welfare. We will show that this is indeed the case. Moreover, we will use two New Keynesian models to assess - in terms of household consumption equivalents - which features of the economic environment make this problem important. In one model, which we call the Standard Model, deviations of the policy rate from its natural rate are substantial, but they have short half lives. In the other model, which we call the Liquid Bonds Model, government bonds are liquid and are imperfect substitutes for both money and illiquid bonds. Only when money and bonds are close substitutes are the deviations of the policy rate from its natural rate short lived. If money and government bonds

4 In the New Keynesian models we consider here, there is no tradeoff between stabilizing inflation and output. Stabilizing inflation maximizes household utility.

5 The intercept term in the original Taylor Rule was the long run value of the natural rate; we have replaced it with the current period's value, which of course will fluctuate over time.

The original specification of the Taylor Rule also contained an output gap. We will suppress the gap in this paper. It is well known that (unless the natural rate of output can be measured accurately) smoothing the output gap is harmful in models where productivity shocks play a prominent role. Here, we leave those well studied issues aside so that we can focus on the natural rate of interest.

6 This analysis assumes that nominal rigidities keep prices from adjusting immediately. 
are not close substitutes, the deviations of the policy rate from the natural rate are substantial and have protracted half lives.

In either of the models, the deviations of the policy rate from its natural rate will depend upon the monetary policy that is in place; we will consider four generic rules:

Rule 1: $i_{t}=\bar{i}+1.5\left(\pi_{t}-\bar{\pi}\right)$

Rule 2: $i_{t}=0.8 i_{t-1}+(1-0.8)\left[\bar{i}+1.5\left(\pi_{t}-\bar{\pi}\right)\right]$

Rule 3: $i_{t}=i_{t-1}+1.5\left(\pi_{t}-\bar{\pi}\right)$

Rule 4: $i_{t}=\left[r_{t}^{n}+E_{t}\left(\pi_{t+1}\right)\right]+1.5\left(\pi_{t}-\bar{\pi}\right)$

$r_{t}^{n}$ is the real natural rate of interest and $\bar{i}$ is the steady state value of the policy rate.

Rule 4 is the variant of the Taylor Rule discussed above. Rule 4 implicitly assumes that the natural rate is observed; since it cannot be observed in practice, Rule 4 must be considered a benchmark. Rule 1 is often used in the literature because it only assumes that the steady state value of the natural rate is known. Rule 2 is also used in the literature since interest rate smoothing is found in estimates of the central bank's policy rule; the coefficients -0.8 and $1.5-$ are typical of what is found in those estimates. Rule 3 is called the first difference rule; Rule A in Levin, Wieland and Williams (1999 and 2003) specified an inflation coefficient of 1.3; we simply use 1.5 across all of the models.

In the Standard Model, the difference in household utility between Rule 1 and Rule 4 is worth a quarter of a per cent of consumption each period, which is a substantial number in the New Keynesian literature. In our preferred parameterization of the Liquid Bonds Model, the difference rises to half a per cent of consumption each period. But in another parameterization where money and bonds are close substitutes, the welfare difference is closer to the gain in the Standard Model. In all cases, the first difference rule provides virtually the same utility as Rule 4 (the full information rule), and it does not require any knowledge of the natural rate of interest.

The first difference rule has been much lauded in the past. In all of the papers we are aware of, an ad-hoc welfare criterion is used instead of household utility - the central bank minimizes a weighted average of the variances of inflation, output and the policy rate. ${ }^{7}$ The variance of the policy rate was a concern because of instrument instability. Orphanides and Williams (2002) and Laxton and Pesenti (2003) are perhaps the papers that are closest to ours. They discussed central bank misperceptions of a constant long run natural rate of interest, and they found that a first difference rule worked quite well in that context. Levin, Wieland and Williams (1999 and 2003) discussed model uncertainty, and found a first difference rule worked quite well in that context; they made no mention of a fluctuating natural rate. Taylor and Williams (2011) provide a nice review of a number of papers in this vein, and provide an extensive bibliography.

Before proceeding to the analysis, we should address two questions. Do bonds have liquidity value? And if so, are they good substitutes for money? The basic premise should not be controversial. US Treasuries facilitate transactions in a number of ways: they serve as collateral in many financial markets, banks hold them to manage the liquidity of their portfolios, and individuals hold them in money market accounts that offer checking services. However, in what follows we will consider both cases - using the Standard Model and the

7 In some cases, there is just a limit placed on the variance of the interest rate. 
Liquid Bonds Model. If bonds do have liquidity value, are money and bonds substitutes or complements? We believe that substitutability is quite low: cash is not used as collateral, and government bonds are not used to pay the barber. However, in what follows, we will consider both cases.

We are of course not the first to study the transaction services of bonds. Early contributions to the literature include: Patinkin (1965), who put both money and bonds in the household utility function; and Friedman (1969), who discussed the optimum quantity of money and (private) bonds. More recent theoretical contributions include: Bansal and Coleman (1996), who used the approach to study the equity premium puzzle and related issues; Holmström and Tirole (1998), who argued that the private sector cannot satisfy its own liquidity needs; Calvo and Végh (1995), who studied the policy implications of liquid bonds; and Linnemann and Schabert (2010), who used a model similar to ours to study macroeconomic policy. The empirical literature finds a liquidity premium on government debt, and moreover that the premium depends upon the quantity of debt. Empirical contributions to the literature include: Friedman and Kuttner (1998), who studied the imperfect substitutability of commercial paper and US Treasuries; Greenwood and Vayanos (2008), who find "that (i) the supply of long-relative to short-term bonds is positively related to the term spread, (ii) supply predicts positively long-term bonds' excess returns"; Krishnamurthy and Vissing-Jorgensen (2010), who find that the spread between liquid treasury securities and less liquid AAA debt moves systematically with the quantity of government debt; Bohn (2010), who presents results similar to those of Krishnamurthy and Vissing-Jorgensen; and Pflueger and Viceira (2011), who decompose "excess return predictability in inflation-indexed and nominal government bonds into liquidity, market segmentation, real interest rate risk and inflation risk" and find "a liquidity premium, which appears systematic in nature".

The rest of the paper proceeds as follows: in Section 2, we outline the two models. In Section 3 , we compare the dynamic properties of the two models. In Section 4, we perform the welfare analysis. And in Section 5, we discuss directions for future research, and implications of our results for current policy making.

\section{The liquid bonds model with a standard model imbedded in It}

The Liquid Bonds Model was developed by Canzoneri, Cumby, Diba and Lopez-Salido (2011). The model extends a standard New Keynesian environment to reflect the fact that government bonds provide liquidity and are imperfect substitutes for money. The model uses Schmitt-Grohé and Uribe's (2004) specification of transaction costs, but it replaces money with a CES aggregate of money and bonds in their definition of velocity. ${ }^{8}$ Imbedded in the Liquid Bonds Model is a Standard Model in which bonds have no liquidity value; it just returns to the original Schmitt-Grohé and Uribe definition of velocity. In the Standard Model, bonds have no liquidity value and are obviously not a substitute for money. The substitutability of money and bonds in the Liquid Bonds Model plays a strong role in the sections that follow. We begin with households and their transaction costs; that is where the action is.

Canzoneri, Cumby, Diba and Lopez-Salido (2011) developed a more structural model in which banks hold money and bonds to manage their deposits. The model we use here makes it easier to build a quantitative model because we can pin down a number of important parameters by matching the sample averages of some key monetary and fiscal variables in US data. 


\subsection{Households and transaction costs}

There is a continuum of households of measure one. Each household supplies labour to every firm; so, in a symmetric equilibrium the households' behaviour will be identical and we can dispense with household indices.

Households maximize

$$
E_{t} \sum_{j=t}^{\infty} \beta^{j-t}\left[\log \left(c_{j}\right)-(1+\chi)^{-1} n_{j}^{1+\chi}\right]
$$

subject to a sequence of budget constraints,

$$
b_{j}+m_{j}+\left(1+\tau_{j}\right) c_{j}+\Upsilon_{j}=w_{j} n_{j}+\frac{\left(l_{j-1} b_{j-1}+m_{j-1}\right)}{\Pi_{j}}+d_{j}
$$

where $c$ is household consumption of a composite final good, $n$ is hours worked, $w n$ is real labour income, and $\tau c$ are household transaction costs. $m$ and $b$ are real money and bond holdings, $I$ is the gross nominal return on a riskless, one-period government bond, $\Pi_{t}\left(\equiv \frac{p_{t}}{p_{t-1}}\right)$ is the gross rate of inflation, $\Upsilon$ represents real lump sum taxes, and $d$ dividends.

We have followed Schmitt-Grohé and Uribe (2004) in assuming that transaction costs are proportional to consumption. The factor of proportionality, $\tau$, is an increasing function of velocity, $v$. Letting $\hat{v}$ be the satiation level of velocity,

$\tau_{t}=\left(A / v_{t}\right)\left(v_{t}-\hat{v}\right)^{2}$

where $A>0$. Schmitt-Grohé and Uribe defined velocity as $v_{t}=c_{t} / m_{t}$, but in the Liquid Bonds Model, we broaden the notion of transaction balances and let

$v_{t}=\frac{c_{t}}{\tilde{m}_{t}}$

where $\tilde{m}_{t}$ is a CES bundle of money and bonds,

$\tilde{m}_{t}^{p}=a^{1-\rho} m_{t}^{\rho}+(1-a)^{1-\rho} b_{t}^{\rho}$

In the Standard Model, we revert to Schmitt-Grohé and Uribe's definition of velocity; that is, $\tilde{m}_{t}=m_{t}$.

The elasticity of substitution in the Liquid Bonds Model is $\xi \equiv 1 /(1-\rho)$. When $\xi<1$, money and bonds are complements; and when $\xi>1$, they are substitutes. As stated previously, this is an important parameter in the model.

Households' first order conditions include:

$w_{t} \lambda_{t}=n_{t}^{\chi}$

$1 / c_{t}=\lambda_{t}\left[1+2 A\left(v_{t}-\hat{v}\right)\right]$

where $\lambda_{t}$ is the real marginal utility of wealth. When real resources are depleted in the purchase of consumption goods, the marginal utility of wealth is less than the marginal utility of consumption. 


$$
\begin{aligned}
& \left\{1-A\left[v_{t}^{2}-(\hat{v})^{2}\right]\left(\frac{a \tilde{m}_{t}}{m_{t}}\right)^{1-\rho}\right\}=\left(l_{t}^{*}\right)^{-1} \\
& \left\{1-A\left[v_{t}^{2}-(\hat{v})^{2}\right]\left(\frac{(1-a) \tilde{m}_{t}}{b_{t}}\right)^{1-\rho}\right\}=\frac{l_{t}}{l_{t}^{*}}
\end{aligned}
$$

where $I_{t}^{*}$ is the gross nominal CCAPM interest rate; that is $\left(I_{t}^{*}\right)^{-1} \equiv \beta E_{t}\left\{\frac{P_{t}}{P_{t+1}} \frac{\lambda_{t+1}}{\lambda_{t}}\right\}$. We will think of $I_{t}^{*}$ as the rate of return on a bond, $b_{t}^{*}$, that does not provide liquidity services.

Equations (9) and (10) imply

$\frac{I_{t}^{\star}-I_{t}}{l_{t}^{*}-1}=\left(\frac{1-a}{a}\right)^{1-\rho}\left(\frac{m_{t}}{b_{t}}\right)^{1-\rho}$

Since $b$ provides transaction services, it will be held at a lower rate of return than $b^{*}$; the spread, $I_{t}^{*}-I_{t}$, will be non-negative in equilibrium. The spread is the pecuniary opportunity cost of holding the bond that does provide transaction services, and $I *-1$ is the opportunity cost of holding money. So, equation (11) says that in the optimal portfolio, the relative price of $m$ and $b$ is equated to the marginal rate of substitution between $m$ and $b$.

When, for example, the central bank conducts an expansionary open market operation, $m_{t} / b_{t}$ will rise; the marginal liquidity value of bonds (relative to money) will rise. This will cause the relative price to rise, and the spread, $I_{t}^{*}-I_{t}$, will increase.

Note also that when money and bonds are complements $(\rho<0)$, a given movement in $m_{t} / b_{t}$ will produce a larger change in the relative price, and in the spread, than when money and bonds are substitutes $(\rho>0)$. This fact will play a role in what follows.

\subsection{Intermediate goods and the final consumption good}

The modelling of the production side of the economy is quite standard. Our description of it can be brief.

A continuum of monopolistically competitive firms, indexed by $j$, produce intermediate goods using a common technology,

$y_{j, t}=z_{t} k n_{j, t}^{\psi}$

Where $k$ is the firm's fixed capital stock, $0<\psi<1$ and $z_{t}$ is a common productivity shock that follows an $\mathrm{AR}(1)$ process:

$\ln \left(z_{t}\right)=\left(1-\rho_{z}\right) \ln \bar{z}+\rho_{z} \ln \left(z_{t-1}\right)+\varepsilon_{t}^{z}$

Where $0 \leq \rho_{z}<1$ and $\bar{z}(=1)$ is the steady state value of $z_{t}$. Competitive retailers buy the intermediate goods and bundle them into the final good, $y_{t}$, using a CES aggregator with elasticity $\eta$.

Intermediate good firms engage in Calvo price setting. Each period, with probability $1-\alpha, \mathrm{a}$ firm $j$ gets to set an optimal new price; if the firm does not get to re-optimize, its price goes 
up automatically by the steady state rate of inflation, $\bar{\Pi}$. Bars over variables indicate a steady state value.

\section{$2.3 \quad$ Goods market clearing}

Households' transaction costs are a drain on resources. The market clearing condition for output is

$y_{t}=\left(1+\tau_{t}\right) c_{t}+g_{t}$

where $g_{t}$ is real government spending on the final good.

\section{$2.4 \quad$ Fiscal policy}

Government spending follows an exogenous AR(1) process

$\ln \left(g_{t}\right)=\left(1-\rho_{g}\right) \ln \bar{g}+\rho_{g} \ln \left(g_{t-1}\right)+\varepsilon_{t}^{g}$

where $0<\rho_{g}<1$ and $\varepsilon_{t}^{g}$ is a spending shock.

The government uses a lump sum tax, $\Upsilon$, to stabilize its debt. The tax rule is

$$
\Upsilon_{t}=\bar{\Upsilon}+\phi_{d}\left(b_{t-1}-\bar{b}\right)
$$

When $\phi_{d}>I / \bar{\Pi}-1$ fiscal policy is stabilizing since tax increases are more than sufficient to pay the interest on any increase in the debt. ${ }^{9}$

\subsection{Steady state and model calibration}

Canzoneri, Cumby, Diba and Lopez-Salido (2011) described the steady state of the Liquid Bonds Model and its calibration in some detail. Our discussion here can be brief, and once again, the interested reader is referred to that paper for a more complete description.

The calibration was based on quarterly US data. Sample averages were used to estimate the steady state values of $\bar{\Pi}, \bar{I}, \bar{b} / \bar{c}, \bar{b} / \bar{m}$, and $\bar{g} / \bar{y} ; \beta$ was set equal to 0.99 (as is usual in quarterly models) to calibrate $\bar{l}^{*}$. Using these estimates, we choose values of the parameters, $a, \hat{v}, A$ to match $\bar{b} / \bar{c}, \bar{b} / \bar{m}$, and $\bar{l}^{*}-\bar{l}$. The other parameters in the model were set equal to values that are standard in the literature: $\alpha=0.75$ implies that the average duration of prices is four quarters; $\eta=7$ implies that the steady state markup is $1.17 ; \chi=1$ implies that the disutility of work is quadratic; $\psi=0.66$ implies that capital's share is one third; and $\theta_{\pi}=1.5$. Parameters in the stochastic processes for government spending and productivity are: $\rho_{g}=0.95, S D\left(\varepsilon^{g}\right) ; \rho_{z}=0.93, S D\left(\varepsilon^{z}\right)=0.01$.

9 This is a passive fiscal policy. Eschewing the Fiscal Theory of the Price Level, we will always assume that fiscal policy is passive. 


\section{3. $p$ rate dynamics}

Observing the natural rate of interest is presumably more important for policy making when the natural rate is moving a lot and the policy rate cannot keep up with it. Movements in the natural rate will of course depend on the source of the shock, but they will also depend on the economic environment: do bonds have liquidity, and if so, are they good substitutes for money, or are they poor substitutes? In what follows, we will consider three cases for the elasticity of substitution: complements $(\xi=0.75)$, unit elasticity $(\xi=1.00)$, and $\operatorname{substitutes}(\xi=1.25)$.

Equally important is presumably whether the policy rate can be made to follow closely the movements in the natural rate. This will of course depend on the policy rule that is in place. We will consider the rules 1 to 4 that were defined in the introduction.

\subsection{Importance of the economic environment}

First, we look at changes in the natural rate, and the deviation of the policy rate from its natural rate, in response to shocks in government purchases and productivity. And we see how these responses depend on the economic environment. For this exercise we assume that monetary policy is guided by Rule 1 .

Figure 1 shows impulse response functions for an increase in government purchases. Rule 1 has a constant intercept term; there is no attempt to follow unobserved fluctuations in the natural rate. The top panel shows responses of the real natural rate of interest, and the bottom panel shows the gap between the policy rate and its natural rate.

Figure 1: Government Spending Shock, Rule 1
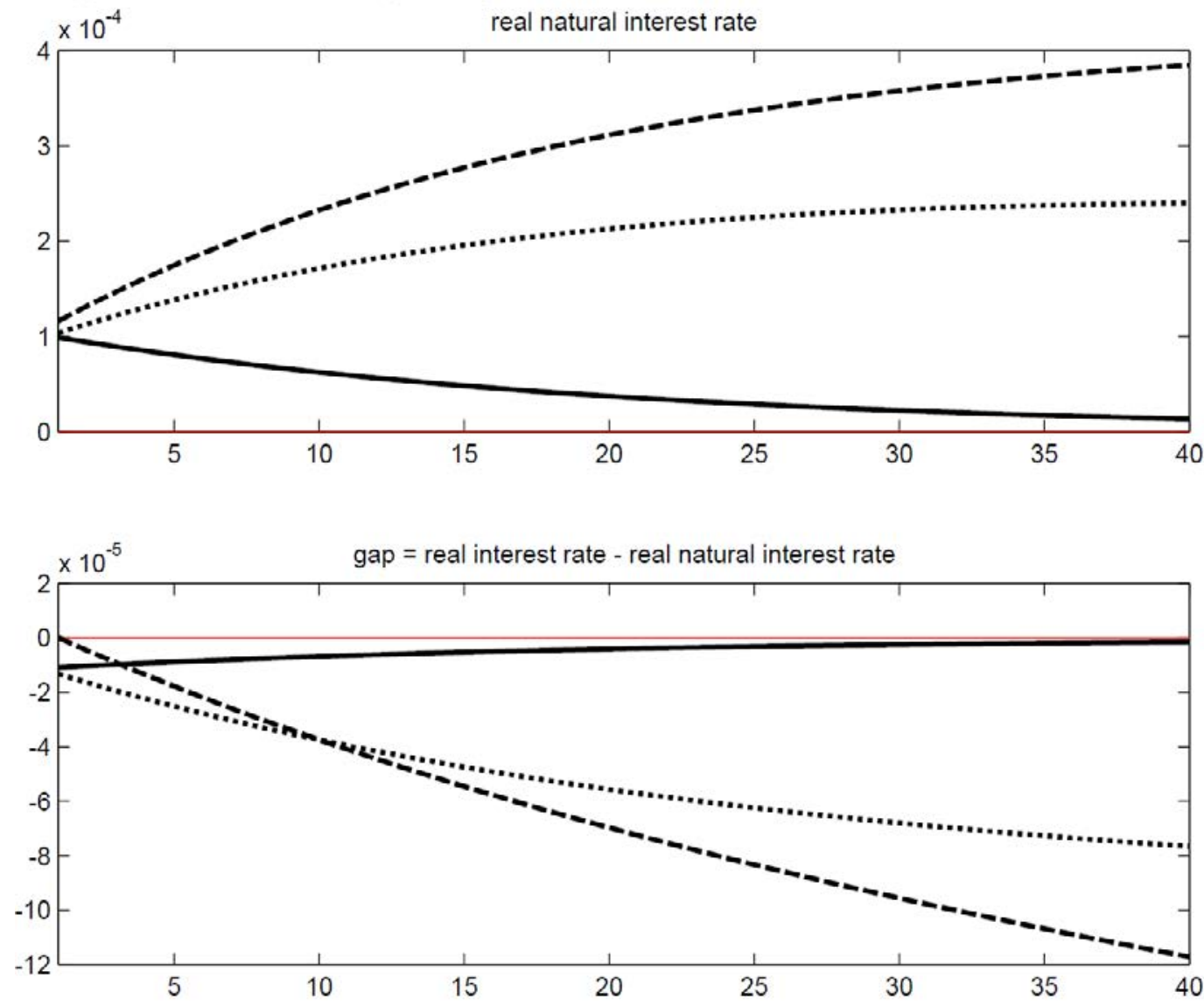

Standard Model: solid line; Liquid Bonds model, compliments: dashed line; substitutes: dotted line 
An increase in government purchases crowds out consumer spending, thus raising the natural rate of interest. In the Standard Model, the increase in the natural rate is moderate, and it dies out relatively quickly. The policy rate rises in response to the inflation caused by the spending increase, but by slightly less than the natural rate. A small gap is created but it too closes rather quickly.

There is a very different response in the Liquid Bonds Model, and that response depends upon whether money and bonds are complements $(\xi=0.75)$ or substitutes $(\xi=1.25)$. In either case, the initial rise in the natural rate is moderate, not unlike the increase in the Standard Model. But here, the natural rate does not return to its steady state value for a very long time. The gap term shows a similar pattern. And these responses are much more pronounced when money and bonds are complements.

Why is this so? In both the Standard Model and the Liquid Bonds Model, the increase in government spending crowds out consumption and the natural rate rises. But when bonds provide liquidity, there is more: as seen in the bottom left panel of Figure 2, a bond financed increase in government spending increases the supply of bonds and that process continues for a very long time. In response to an innovation in government purchases of one per cent of quarterly GDP, debt continues to rise for more than 11 years, and at its peak, the increase is nearly 20 per cent of quarterly GDP.

Figure 2: Government Spending Shock, Rule 1
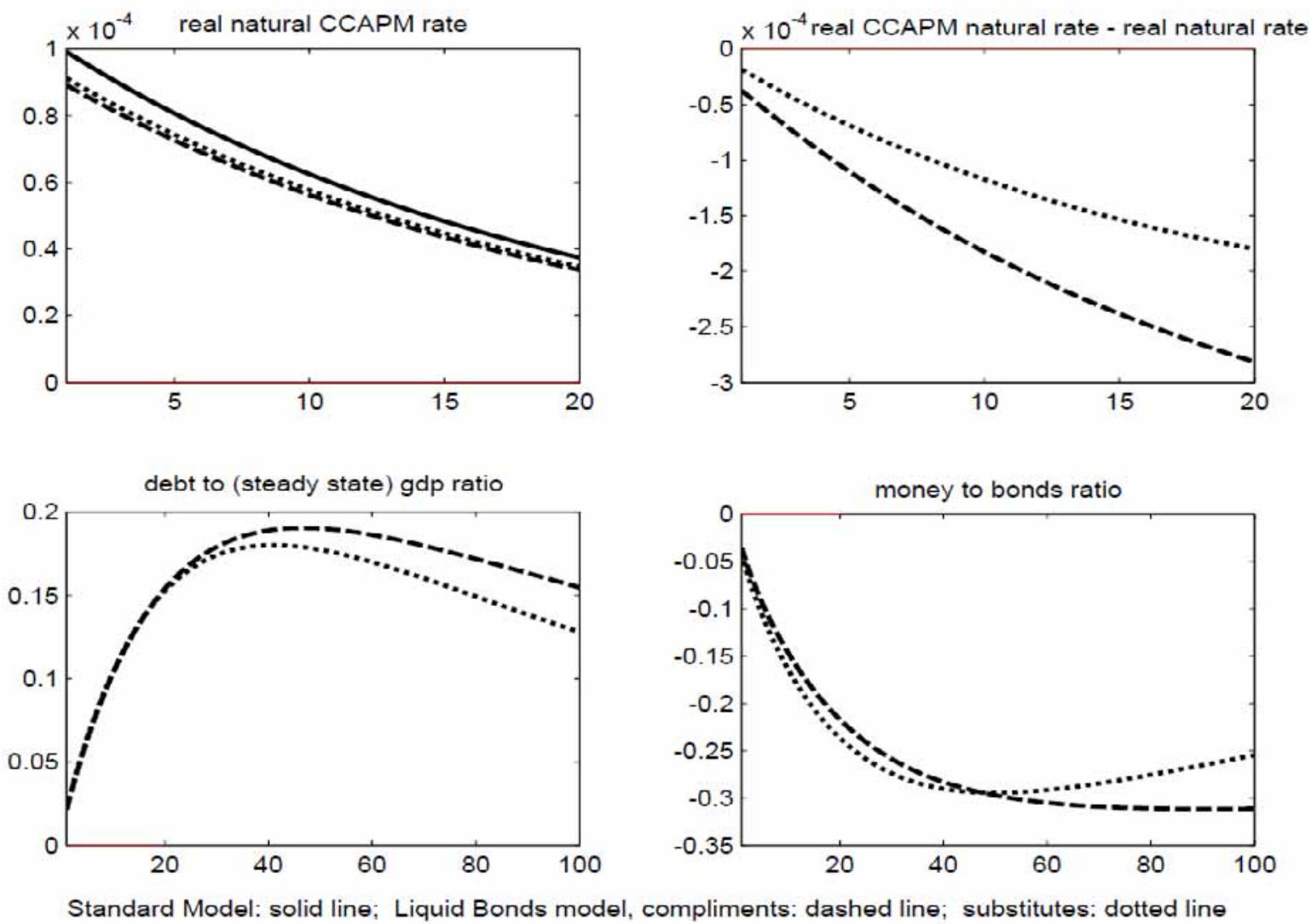

As the debt rises and $m_{t} / b_{t}$ falls, the marginal liquidity value of bond holdings declines, which raises the natural rate and reduces the spread, $I^{*}-l$. To see this, let $\Delta x$ be the difference in the response of variable $x$ between any two of the three models (the Standard Model, the Liquid Bonds Model where money and bonds are complements, and the Liquid Bonds Model where the two are substitutes). We can then decompose the difference in the natural rates into, 


$$
\Delta l^{N}=\Delta l^{*, N}-\Delta\left(I^{*, N}-I^{N}\right)
$$

The upper left panel of Figure 2 shows that there is very little difference between the real natural CCAPM rates in the three models. So, the first term on the RHS of equation (16) is close to zero, and the differences in the natural rate of interest are due essentially to differences in the marginal liquidity value of government debt, which is reflected in the smaller spread. Thus, the natural rate rises by more in the Liquid Bond Models than in the Standard Model. And because the supply of bonds grows over time, the difference in the real natural rates of interest rises over time as well.

The next question is, why is the response of the natural rate so much larger when money and bonds are complements? A fiscal expansion makes $m / b$ fall. ${ }^{10}$ This leads to a larger decline in the marginal liquidity value of bonds when money and bonds are complements. From equation (11), when money and bonds are complements (and $\rho$ is low), the decrease in $m / b$ results in a larger change in the marginal liquidity value of bonds and a larger change in the spread, $l^{*}-l$. As seen in Figure 2 , the ratio of money to bonds is virtually the same in both cases so that essentially all the difference in the natural rates arises from the greater response in the spread, $I^{*}-l$, to a given change in $\mathrm{m} / \mathrm{b}$ when money and bonds are complements.

The increase in the natural rate in the Liquid Bonds Model is relatively moderate: an innovation in government purchases of one per cent of GDP raises the annualized natural rate by about 35-50 basis points after five years (depending on the version of the model) and about $40-60$ basis points after 10 years. But the increase in the natural rate is extremely persistent, reflecting debt dynamics. As seen in Figure 2, debt continues to grow, and $\mathrm{m} / \mathrm{b}$ continues to decline, for more than 10 years following a persistent shock to government purchases. As a result, the marginal liquidity value of debt continues to decline, and the natural rate continues to rise, for more than 10 years before these changes begin to reverse. As we will see in the next section, failing to adjust monetary policy in response to these moderate but extremely persistent changes in the natural rate of interest has significant welfare implications.

These differences across models in the marginal liquidity value of government bonds explain the differences in the behaviour in the gap between the policy rate and the natural rate as well. In all three cases, the policy rate, which follows Rule 1, rises in response to inflation. Initially, the gaps between the policy rates and the natural rates are all similar and small. Over time, however, as the policy rates respond only to inflation, and the natural rates move with the accumulating bond supplies, the gaps in either one of the Liquid Bonds Models grow. And because the rise in the natural rate is greater when money and bonds are complements, the gap between the policy rate and the natural rate is greater as well. ${ }^{11}$

A productivity shock, unlike a shock to government purchases, does not have a direct effect on government liabilities, $m+b$. But, monetary policy changes their composition, and this has real effects through (11). Figure 3 shows that a productivity shock has sizable effects on the natural rate of interest; however, they are not long lasting. A positive productivity shock

10 A deficit financed increase in government purchases increases $m+b$. Monetary policy responds to the increasing inflation with an open market sale of bonds. The net effect is a fall in $\mathrm{m} / \mathrm{b}$.

11 The gap between the policy rate and the natural rate is less than the rise in the natural rate. Because the policy rule fails to take into account the rise in the natural rate, the policy rate is set too low. As a result, inflation rises more in the Liquid Bonds Model and is persistent. The policy rule raises the real policy rate when inflation rises, thereby reducing the gap somewhat. 
increases supply, and this drives the natural rate down. The effect is more pronounced in the Liquid Bonds Model, but the differences, while long lasting, are not large.

Figure 3: Productivity Shock, Rule 1
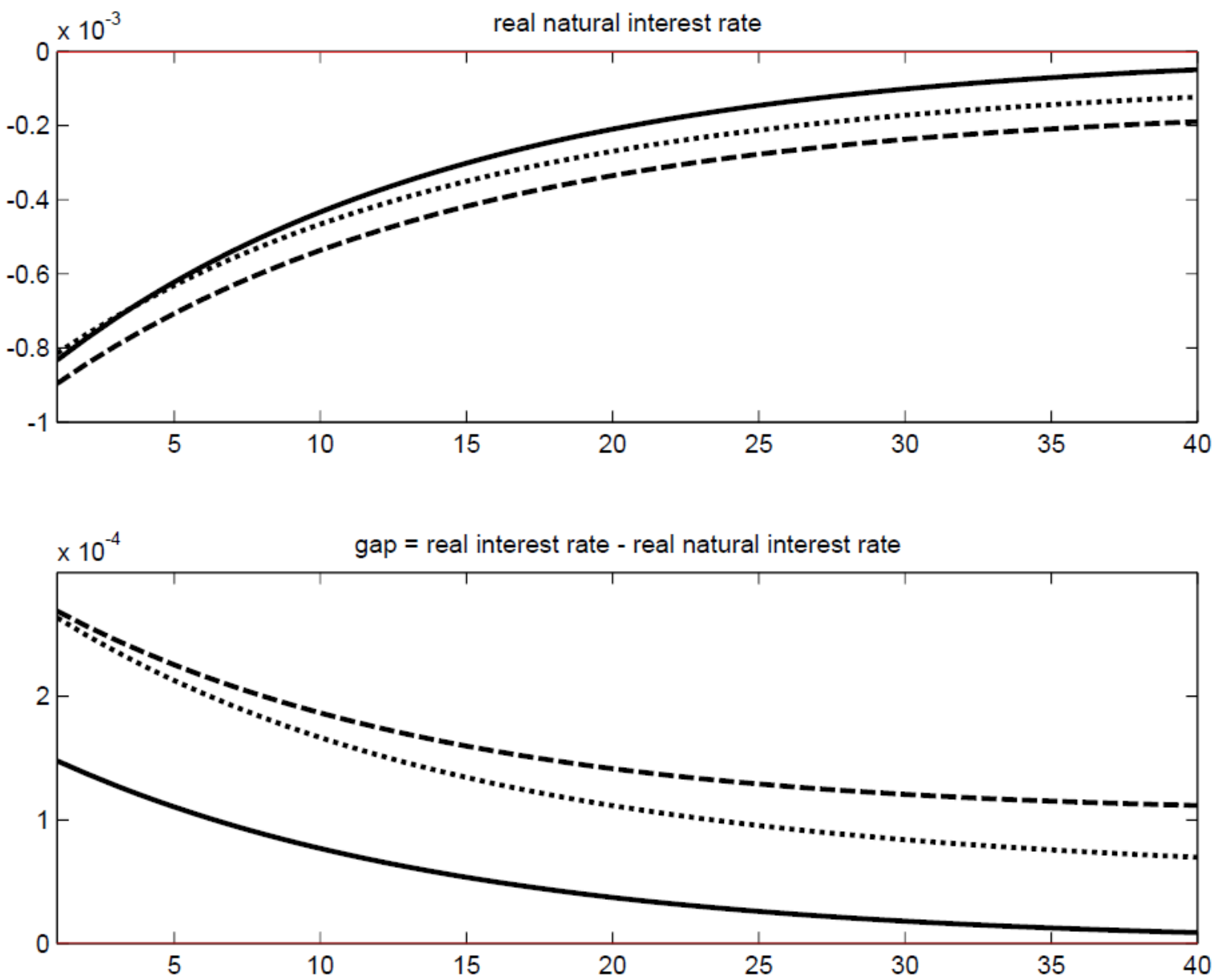

Standard Model: solid line; Liquid Bonds model, compliments: dashed line; substitutes: dotted line

Summing up: In the Standard Model, government spending shocks cause the natural rate to rise moderately, and productivity shocks cause the natural rate to fall moderately. But in each case, movements in the natural rate die out relatively quickly. Moreover, the policy rate tracks movements in the natural rate rather closely. When bonds provide liquidity, roughly the same conclusions hold with respect to productivity shocks. However, bond financed government spending shocks induce sustained movements in the natural rate (because of sticky prices); Rule 1 cannot make the policy rate keep up. In this case, observing and tracking the natural rate would seem to be most important. Finally, this last result is more pronounced when money and bonds are complements; when they are substitutes, a given change in the money to bonds ratio does not cause as large a swing in the relative prices of the two assets or the interest rate spread. And simulations show that movements in the spread are closely related to movements in the natural rate.

\subsection{Importance of the Interest Rate Rule}

The real natural rate of interest comes from the flexible price solution, and monetary policy cannot affect that solution. However, some policy rules are better than others in making the policy rate track its natural rate. Rule 1 has a constant intercept term, set at the steady state value of the nominal natural rate of interest; this rule makes no direct attempt to track short run fluctuations in the natural rate. Neither does Rule 3, the first difference rule. But there is 
no intercept term in it, and it may track the natural rate better than Rule 1 . Why? A unit root process may be better at picking up prolonged movements in the natural rate. Rule 4 assumes that the natural rate is actually observed; this rule must be considered a benchmark case, since Rule 4 cannot be implemented in practice.

In this section, we examine the performance of these three rules in the Standard Model and in our Liquid Bonds Model. ${ }^{12}$ We begin with the Liquid Bonds Model; for this exercise, we set the elasticity of substitution between money and bonds equal to one $(\xi=1)$; this case is right in between the complements $(\xi=0.75)$ case and the substitutes $(\xi=1.25)$ case.

Figure 4 shows responses in the interest rate gap to government spending and productivity shocks. As might be expected, Rule 1 does a very poor job of tracking the natural rate. For an increase in government purchases, the interest rate gap is still widening after five years. This is, once again, because a bond financed expansion reduces the marginal liquidity of bonds and induces a protracted increase in the natural rate. The rule fares somewhat better for an increase in productivity: the interest rate gap has a half life of four years and a quarter. Rule 3 does a much better job of tracking the natural rate: the half life is just two quarters for either of the shocks. And, not surprisingly, Rule 4 tracks the natural rate perfectly.

Figure 4: Liquid Bonds Model, unit elasticity, Policy Rules
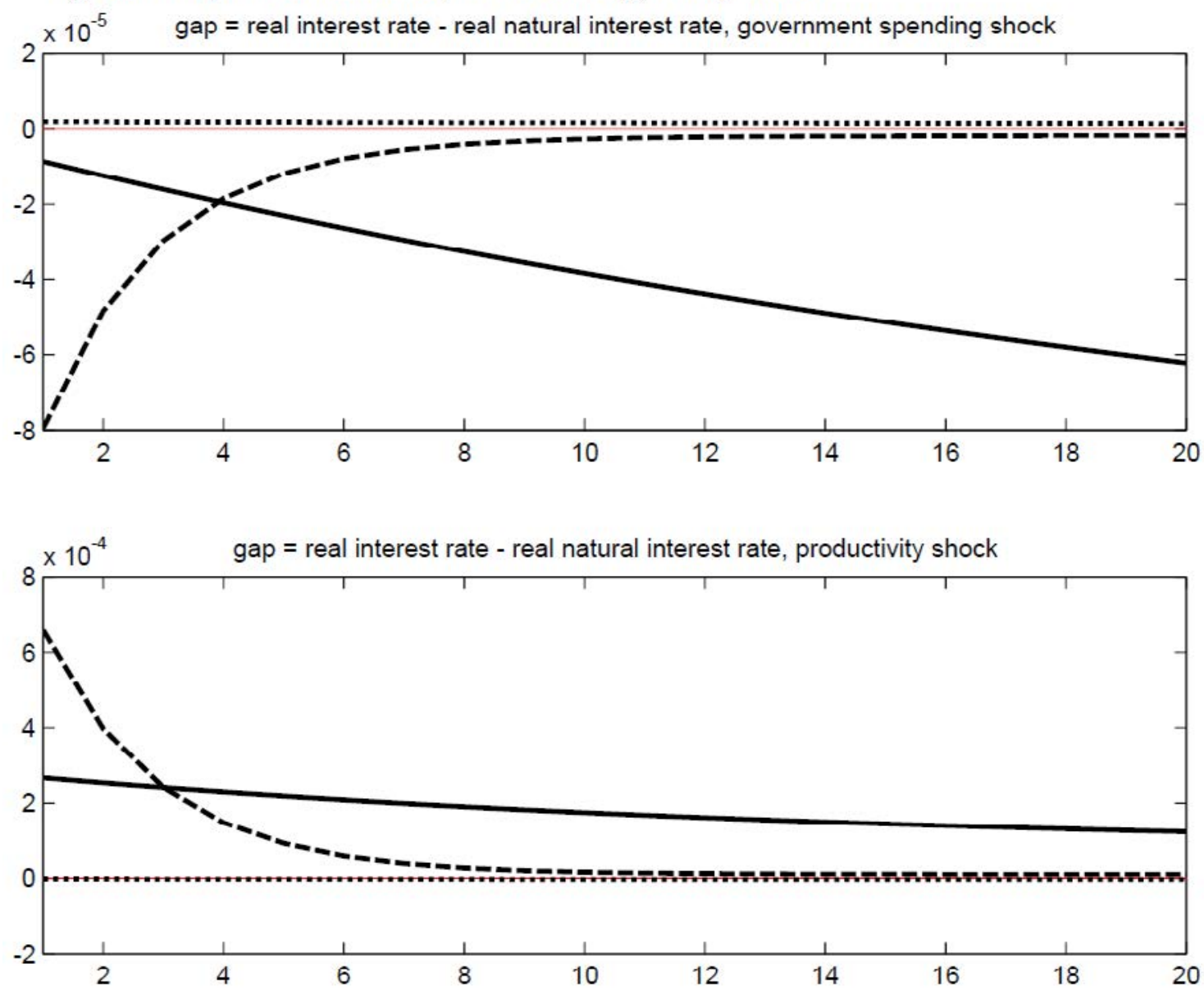

Rule 1: solid line; Rule 3: dashed line; Rule 4: dotted line

12 include it in this section. 
Figure 5 gives the analogous results for the Standard Model. Since bond financed fiscal expansions do not directly affect liquidity, Rule 1 fares much better in the case of an increase of government spending: the interest rate gap has a half life of just four years. Rule 1 also does somewhat better in the case of a positive productivity shock: the gap has a half life of less than three years. Rule 3 appears to fare a little better than in the Liquid Bonds Model, though the half life of the gap is still two quarters for either shock. And once again, Rule 4 tracks the natural rate perfectly.

Figure 5: Standard Model, Policy Rules
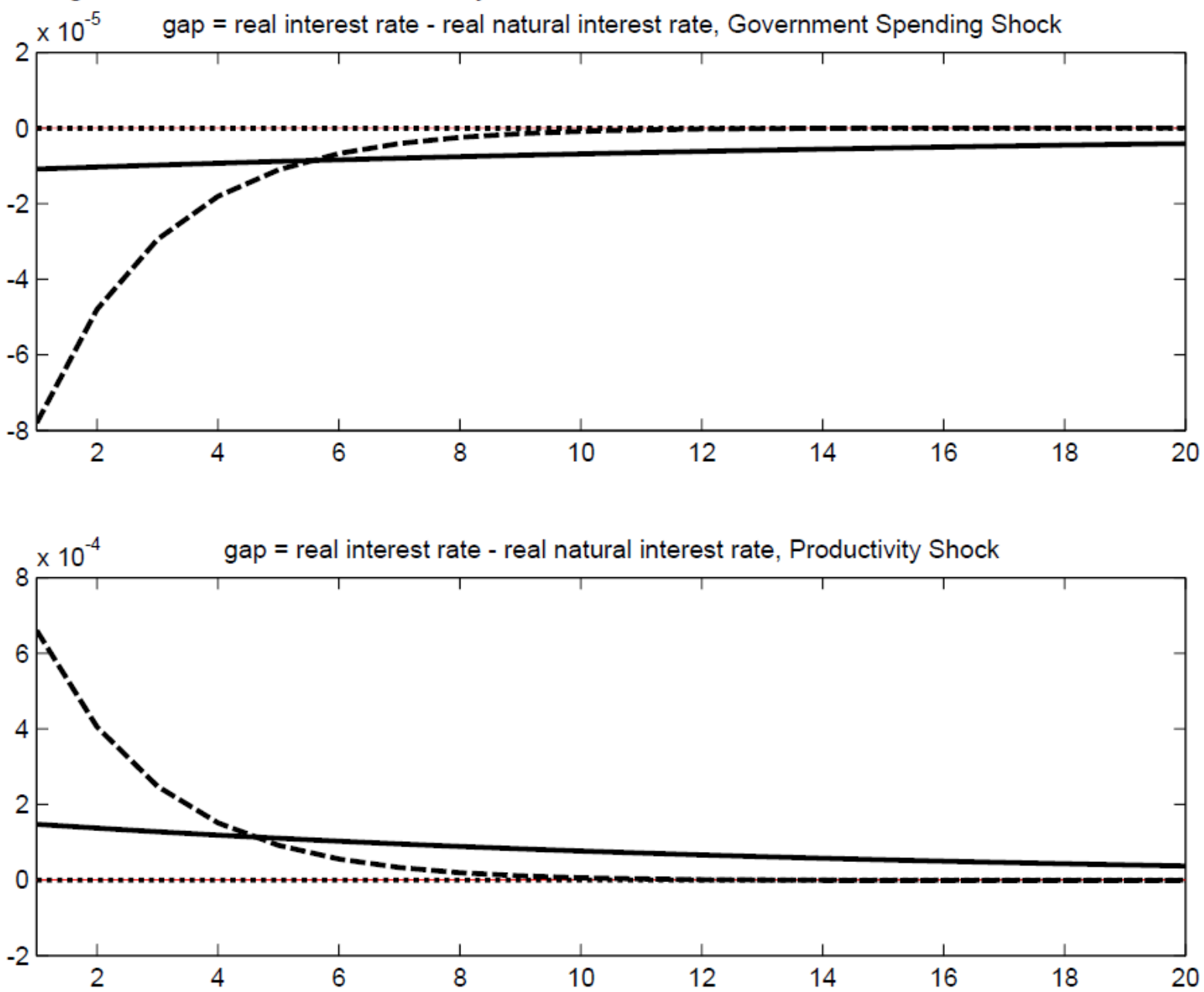

Rule 1: solid line; Rule 3: dashed line; Rule 4: dotted line

Summing up: Rules that quickly bring the policy rate in line with its natural rate are presumably better policies, a normative question we pursue in Section 4. Rule 1 makes no explicit attempt to track the natural rate, and in fact, it does a bad job of it. This is especially true for bond financed spending increases in the Liquid Bonds Model. Rule 3, the first difference rule, does a much better job, in both models and for both government spending shocks and productivity shocks. This may be because a unit root process is better at picking up prolonged movements in the natural rate. Rule 4 assumes that the natural rate of interest is directly observable, and as a consequence it tracks the natural rate perfectly; however, it is not implementable in practice. 


\section{Is observing the natural rate of interest important in terms of household utility?}

The previous section conducted a positive analysis of three of the policy rules; here we study the normative performance of rules 1 to 4 . The notion guiding the positive analysis was that good policy rules make the policy rate track its natural rate closely. If that notion is correct, then Rule 2 is better than Rule 1, Rule 3 is better than Rule 2 and Rule 4 is better than Rule 3. Here, we confirm that notion, and we ask whether the gain from going from one rule to the next is quantitatively important. We also compare different economic environments in this regard; that is, we study the Standard Model and the Liquid Bonds Model. In the latter we consider cases where money and bonds are complements $(\xi=0.75)$ and cases where they are substitutes $(\xi=1.25)$.

The metric we use is the expected discounted value of household utility, conditional on the economy starting in its steady state. But since this metric has no clear meaning, we follow the custom of comparing the policy rules in terms of consumption units: what per cent of consumption would households be willing to give up each period - assuming that the work effort is held constant - to move from one rule to the next.

Table 1 presents the welfare results. In it, the comparisons are all with respect to Rule 1 , the original Taylor Rule (minus the output gap), with a constant intercept term.

Table 1

Welfare comparisons, steady state consumption gained over Rule 1 (in per cent)

\begin{tabular}{l|c|c|c}
\hline & Standard model & $\begin{array}{c}\text { LB model: } \\
\text { complements }\end{array}$ & LB Model: substitutes \\
\hline Rule 1 & $\mathrm{X}$ & $\mathrm{X}$ & $\mathrm{X}$ \\
Rule 2 & 0.11 & 0.13 & 0.06 \\
Rule 3 & 0.25 & 0.51 & 0.29 \\
Rule 4 & 0.25 & 0.50 & 0.29 \\
\hline
\end{tabular}

Rule 2 is the version of the Taylor Rule that is used in much of the New Keynesian literature; it has a constant intercept term and interest rate smoothing. Households would give up a little over a tenth of a per cent of consumption to have interest rate smoothing in either the Standard Model or the Liquid Bonds Model with complements; in the Liquid Bonds Model with substitutes, it is only half as much.

Rule 3, the first difference rule, does much better when compared with Rule 1: a quarter of a per cent in the Standard Model, and half a per cent in the Liquid Bonds Model with complements. These are large numbers by the standards of the New Keynesian literature. And the fact that the first difference rule does particularly well in the Liquid Bonds Model with complements is perhaps not surprising; in that environment, government spending shocks cause sustained movements in the natural rate that are hard for Rule 1 or Rule 2 to track. The gain is not as large in the Liquid Bonds Model with substitutes: about a third of a per cent of consumption.

It is interesting to note that the first difference rule performs virtually as well as Rule 4, the full information rule that assumes the natural rate can be observed. To implement the first difference rule, there is no need to observe the natural rate. It may be somewhat surprising 
that the first difference rule does so well, but it is consistent with earlier results discussed in the Introduction.

Summing up: In the Standard Model, households would be willing to give up a quarter of a per cent of consumption to replace the original Taylor Rule with a full information rule that requires direct observation of the natural rate of interest. In the Liquid Bonds Model where money and bonds are complements, and government spending shocks cause sustained movements in the natural rate, households would be willing to give up half a per cent of consumption to get the full information rule. Finally, the first difference rule performs virtually as well as the full information rule in all of the cases. Presumably that is because a unit root process can better pick up sustained movements in the natural rate.

\section{Conclusion}

In Section 3, we showed that - in some economic environments and with some standard monetary policy rules - shocks to the economy can make the natural rate of interest deviate substantially from its steady state value for a very long time. In Section 4, we showed that in this kind of environment, household utility improves significantly when the monetary policy rule can make the policy rate track its natural rate precisely. Moreover, a first difference rule - a rule that does not require any information about the natural rate - performs virtually as well as the full information rule. More detailed results have already been summarized at the ends of the preceding sections. They need not be repeated here.

The actual choices of central banks are not limited to rules with no information or (impractical) rules with full information. It would be interesting to explore rules that use the central bank's perceptions of the natural rate; that is, rules that replace the intercept term in the original Taylor Rule with the central bank's perception of the natural rate. This would be difficult to do, since it would require one to take a stand on how to model the central bank's perceptions.

Finally, there is a timely lesson to be learned from our analysis. As of this writing, many OECD countries are undertaking, or contemplating, large cuts in government spending to stabilize their sovereign debts. If bonds do provide liquidity services, then our results suggest that the natural rate of interest will be moving a lot. Central banks will find it difficult to track the natural rate, and the first difference rule seems to be made for just this situation.

\section{References}

Bansal, Ravi and John Coleman, 1996, "A Monetary Explanation of the Equity Premium, Term Premium, and Risk-Free Rate Puzzles", Journal of Political Economy, No 6, pp 1135-1171.

Bohn, Henning, 2010, "The Economic Consequences of U.S. Government Debt", mimeo.

Calvo, Guillermo and Carlos Végh, 1995, "Fighting inflation with high interest rates: the small open economy case under flexible prices", Journal of Money, Credit and Banking, Vol 27, No 1, pp 49-66.

Canzoneri, Matthew, Robert Cumby, Behzad Diba and David Lopez-Salido, 2008, "Monetary Aggregates and Liquidity in a Neo-Wicksellian Framework", Journal of Money, Credit and Banking, Vol 40, No 8, December, pp 1667-1698.

Canzoneri, Matthew, Robert Cumby, Behzad Diba and David Lopez-Salido, 2011, "The Role of Liquid Government Bonds in the Great Transformation of American Monetary Policy", Journal of Economic Dynamics and Control, Vol 35, Issue 3, pp 282-294. 
Curdia, Vasco, Andrea Ferrero, Ging Cee Ng and Andrea Tambalotti, 2011, "Evaluating Interest Rate Rules in an Estimated DSGE Model", FRBNY Staff Report No 510, August 2011.

Friedman, Benjamin and Kenneth N Kuttner, 1998, "Indicator Properties Of The Paper-Bill Spread: Lessons From Recent Experience", The Review of Economics and Statistics, MIT Press, Vol 80(1), pp 34-44, February.

Friedman, Milton, 1969, The Optimum Quantity of Money and Other Essays, Aldine Publishing Company, Chicago.

Greenwood, Robin and Dimitri Vayanos, 2008, "Bond Supply and Excess Bond Returns", NBER Working Paper Series No 13806.

Holmström, Bengt and Jean Tirole, 1998, "Private and Public Supply of Liquidity", The Journal of Political Economy, Vol 106, No 1, February, pp 1-40.

Krishnamurthy, Arvind and Annette Vissing-Jorgensen, 2010, "The Aggregate Demand for Treasury Debt", mimeo.

Laubach, Thomas and John C Williams, 2003, "Measuring the Natural Rate of Interest", Review of Economics and Statistics, 85(4), November, pp 1063-1070.

Laxton, Douglas and Paolo Pesenti, 2003, "Monetary Policy Rules for Small, Open, Emerging Economies", Journal of Monetary Economics, Vol 50 (July), pp 1109-1146.

Levin, Andrew, Volker Wieland and John Williams, 1999, "Robustness of Simple Monetary Policy Rules under Model Uncertainty", In Monetary Policy Rules, John Taylor (Ed), pp 263-299. Chicago: University of Chicago Press.

Levin, Andrew, Volker Wieland and John Williams, 2003, "The performance of forecast based policy rules under model uncertainty", American Economic Review, 93 (3), pp 622-645.

Linnemann, Ludger and Andreas Schabert, 2010, "Debt Nonneutrality, Policy Interactions, And Macroeconomic Stability", International Economic Review, Vol 51(2), pp 461-474.

Orphanides, Athanasios and John C Williams, 2002, "Robust Monetary Policy Rules with Unknown Natural Rates", Brookings Papers on Economic Activity, 2:2002, pp 63-118.

Patinkin, Don, 1965, Money, Interest, and Prices: An Integration of Monetary and Value Theory, 2nd ed, Harper \& Row, New York.

Pflueger, Carolin and Luis Viceira, 2011, "An Empirical Decomposition of Risk and Liquidity in Nominal and Inflation Indexed Government Bonds", NBER Working Paper No 16892, March.

Schmitt-Grohé, Stephanie and Martin Uribe, 2004, "Optimal Fiscal and Monetary Policy under Sticky Prices", Journal of Economic Theory, 114, February, pp 198-230.

Taylor, John and John Williams, 2011, "Simple and Robust Rules for Monetary Policy", in Handbook of Monetary Economics, Vol 3, Benjamin Friedman and Michael Woodford (editors), Elsevier, 2011. 